\title{
ASPECTOS GENÉTICOS DO FATOR MASCULINO NA INFERTILIDADE ${ }^{1}$
}

\author{
ASPECTS OF THE MASCULINE FACTOR IN THE INFERTILITY \\ LOS ASPECTOS DEL FACTOR MASCULINO EN LA ESTERILIDAD
}

Gustavo Henrique Boff Maegawa* Lidio J air R. Centa*

\begin{abstract}
RESUMO: Descreve diversas causas genéticas de infertilidade masculina, as alterações cromossômicas e moleculares que podem estar presentes em pacientes com "oligo ou azoospermia idiopática". Faz, também, uma revisão das técnicas de diagnóstico pré-implantacional disponíveis atualmente. 0 estudo está centrado nos aspectos genéticos do fator masculino da infertilidade de casais. S ua importância consiste no dever ético de se analisar caso a caso, quando se opta por técnicas de injeção intra-citoplasmática de espermatozóides (ICSI), porque uma significativa fração dos indivíduos com "oligo ou azoospermia idiopática", apresentam alterações genéticas em seus espermatozóides ou outras células do epitélio germinativo. A probabilidade da criança apresentar doença genética é grande. Deste modo, a ICSI não é a opção mais indicada para casais que enfrentam este problema.
\end{abstract}

PALAVRAS CHAVE: Infertilidade masculina; Genética; Anormalidades dos cromossomos sexuais.

\section{INTRODUÇÃO}

O fator masculino na infertilidade tem se tornado cada vez mais importante na investigação de casais inférteis. Tal fato representa uma queda considerável na qualidade do esperma entre indivíduos saudáveis e jovens nos últimos anos (Auger et al. 1995). Face a esta situação, novas opções terapêuticas têm surgido, que permitem o tratamento de casos de intensa oligospermia e azoospermia.

Alguns investigadores (Vogt et al. 1995; Chandley et al. 1995) observaram que certos pacientes que apresentavam "oligo ou azoospermia idiopática" tinham alterações genéticas como microdeleções que, entre outras, localizavam-se no gene Yq 11. Estudos citogenéticos não são capazes de detectá-lo, mas estudos moleculares com a técnica de R eação em Cadeia da Polimerase (PCR), sim. Além disso, a ausência congênita de vasos deferentes foi identificada em formas leves, ou formas genitais puras de fibrose cística (Anguiano et al. 1992).

J á que indivíduos portadores de anormalidades genéticas foram quase sempre estéreis no passado, atualmente, utilizando-se a injeção introcitoplasmática de espermatozoides (ICSI) com espermatozóides ou espermátides obtidos através de aspiração micro-epidimal (MESA) ou extração testicular (TESE), este problema pode ser minimizado, mas há risco considerável de trans missão de defeitos genéticos à prole. Um bom exemplo são as anormalidades ligadas ao cromossomo Y que são transmitidas para descendentes do sexo masculino.

Devido a este fato, há muitas discussões em relação a adoção ou não destes meios terapêuticos em defeitos espermatogênicos idiopáticos. Pode-se decidir por não utilizá-las em determinados casais, pois a saúde e o bem-estar da futura criança é que deve orientar este impasse, apesar da constante pressão de grande parte dos casais. Este problema poderá ser solucionado com o advento de novas e revolucionárias técnicas de diagnóstico molecular pré-implantacional e a identificação de genes responsáveis por doenças genéticas pelo Projeto do Genoma Humano (HUGO).

\footnotetext{
Extraído do trabalho de monografia apresentada no estágio eletivo de tocoginecologia.

* Aluno do curso de graduação em Medicina do Setor de Ciências da Saúde da Universidade Federal do Paraná.

** Médico. Professor Assistente 4 da disciplina de Reprodução Humana do Curso de Medicina da Universidade Federal do Paraná. Departamento de

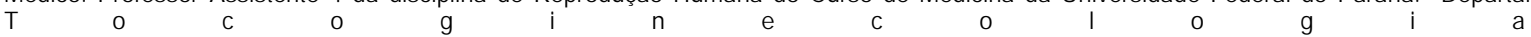




\section{REVISÃO DE LITERATURA}

\section{ASPECTOS GERAIS SOBRE INFERTILIDADE MASCULINA}

O fator masculino na infertilidade representa 25 a 30\% dos casais inférteis (J ones etal. 1993). Devido a este fato, deve-se sempre fazer uma avaliação do fator masculino quando se realiza a investigação de infertilidade. Esta avaliação deve, basicamente, compreender histórico, exame físico e espermograma.

A infertilidade masculina não consiste em uma doença, mas em uma síndrome que resulta de desordens adquiridas ou congênitas. A maioria dos indivíduos inférteis são saudáveis, assintomáticos e têm poucas alterações ao exame físico, no entanto, a infertilidade pode ser a manifestação inicial de uma doença sistêmica, pois a maioria dos homens inférteis apresenta oligozoospermia (redução no número de espermatozóides inferior a 20x106 espermatozóides $/ \mathrm{ml}$ ), astenozoospermia (motilidade inadequada) ou teratozoospermia (espermatozóides com morfologia anormal), que indica alterações quantitativas e qualitativas na espermatogênese (Seibel, 1996).

\section{CAUSAS DIVERSAS DE INFERTILIDADE MASCULINA}

Existem várias causas de infertilidade masculina. Elas podem ser classificadas em insuficiência testicular primária, que resulta de anormalidade em ambos testículos, que por sua vez, pode ser congênita ou adquirida. Dentre os distúrbios congênitos que produzem falência testicular primária temos: Síndrome de Klinefelter (47,XXY e variantes), masculino $X X Y$, criptorquidismo, anárquia congênita (síndrome da ausência testicular), síndrome Naonan, distrofia muscular miotônica, anemia falciforme. Sendo que este distúrbio é adquirido por orquides: caxumba piogênica e traumática, neoplasia maligna: de células germinativas, leucemia e linfoma, torção de cordão espermático, varicocele, lesão de medula espinhal, doença hepática, insuficiência renal, fibrose retroperitoneal, drogas, irradiações e idade (Seibel et al.,1997). Além disso, a função testicular pode ser comprometida por uma doença sistêmica aguda ou crônica. A insuficiência hepática crônica, que está associada freqüentemente à infertilidade, disfunção sexual e redução da androgenização, é um bom exemplo. Neste grupo, pode-se citar ainda: síndrome da imunodeficiência adquirida (AIDS), exercício físico prolongado e intenso, tireotoxicose e até envelhecimento. Drogas também podem levar à infertilidade.

Drogas e toxinas que podem alterar a função reprodutiva (Seibel et al., 1997): exposição ocupacional disulfeto de carbono, clordectone, chumbo, etileno glicol, estrogênio; drogas prescritas associadas com disfunção reprodutiva - agentes quimioterápicos, andrógenos, sulfasalazina; drogas que alteram a função sexual masculina - inibidores da síntese de testosterona (espirolactona, acetato de ciprosterona, cetoconazol) antagonistas andrógenos (espirolactona, flutamida, acetato de ciprosterona, cimetidina) inibidores da função erétil e ejaculação; Anti-hipertensivos - metildopa, reserpina, B-bloqueadores, clonidina; Neurolépticos fenotiazidas, butirofenona, lítio; Antidepressivos - tricíclicos, inibidores da monoamina oxidase; Anticolinérgicos; Drogas recreacionais - etanol, marirruana, opiáceos, cigarros.

Tanto as drogas prescritas pelo médico, de determinado paciente, quanto as drogas de uso social como maconha, opiáceos, álcool, por exemplo, alteram a função testicular diretamente ou suprem a secreção de gonadotrofinas (LH - hormônio luteinizante, FSH - hormônio estimulador do folículo) gerando deficiência de androgênio ou parada da espermatogênese.

A obstrução do trato genital tem sido citada como responsável por 3 a 13\% dos casos (J equier et al. 1984). As disfunções ejaculatórias, fatores imunológicos (anticorpos anti-esperma), fatores térmicos, disfunções endócrinas (ex. secreção pulsátil de LH insuficiente) constituem outras causas de infertilidade masculina.

\section{FATORES GENÉTICOS NA INFERTILIDADE MASCULINA}

Nos últimos anos o conhecimento sobre a etiologia genética da infertilidade tem ampliado graças aos avanços neste campo, pois diferentes anormalidades genéticas têm sido identificadas, sendo que atualmente representam uma parte considerável na etiologia deste problema.

A seguir apresenta-se as causas mais comuns de infertilidade masculina. 


\section{ANORMALIDADES CROMOSSÔMICAS}

Kjesseler (1966), estudando um grupo de pacientes de uma clínica de infertilidade, observou que a freqüência de anormalidades cromossômicas aumentava à medida em que a redução do número de espermatozóides se acentuava.

Em pacientes azoospérmicos, a freqüência das alterações cromossômicas giram em torno de 10 a $15 \%$ (Lidgaard et al., 1998). Destes, 92\% são anormalidades localizadas em cromossomos sexuais, restando apenas $8 \%$ nos cromossomos autossômicos (Assche et al., 1996).

A síndrome de Klinenfelter e suas variantes representa cerca de $4 \%$ dos indivíduos inférteis e $11 \%$ daqueles azoospérmicos (De Braekeleer et al., 1991). Esta síndrome ocorre com uma freqüência 50 vezes maior em homens azoospérmicos em relação àqueles normais. Porém, é importante ressaltar que nem todo paciente com síndrome de Klinenfelter apresenta azoospermia.

Indivíduos com 47 XYY (freqüência de 1: 1000 homens) podem apresentar uma espermatogênese anormal, além de outras características fenotípicas, como alta estatura, distúrbios de comportamento e risco aumentado para leucemias.

Pacientes com oligozoospermia, apresentam cerca de 3 a 8\% de alterações cromossomicas (P rauer et al., 1997). Na oligozoospermia, os desarranjos nos cromossomos autossômicos, representam aproximadamente $2 / 3$ restando $1 / 3$ para os cromossomos sexuais. A alteração mais freqüente consiste nas translocações Robertsonianas $t(13,14)$. Deste modo, à proporção em que a contagem de espermatozóides decresce, as anormalidades cromossômicas são mais freqüentes, sendo que as sexuais prevalecem sobre as autossômicas.

Se forem analisados indivíduos normais, cerca de $10 \%$ terão espermatozóides com alterações cromossômicas (Assche et al., 1996).

A importância destes estudos reside no fato de que a maioria destes indivíduos, há alguns anos atrás, não podiam conceber, e que atualmente, com as técnicas de injeção intracitoplasmática de espermatozóides (ICSI) isto já é possível, apesar de que o risco de transmissão das anormalidades cromossômicas elevou-se. Isto faz com que exames de deteç̧ão de cromossomopatias e outras alterações genéticas se tornem fundamentais na investigação ou redução deste problema.

\section{DELEÇÕES NO CROMOSSOMOY}

No braço longo do cromossomo $Y$, um gene ou um complexo de genes chamado de fator de azoospermia (AZF) tem sido localizado, o qual é considerado como responsável pela produção de um ou mais fatores, até agora não identificados, necessários para a espermatogênese normal. A região do AZF tem sido subdividida em AZF-a, AZF -b , AZF-c (Vogt et al., 1996). A lesão das últimas duas regiões parece resultar em azoospermia ou severa oligospermia. A região AZF-c, inclui o chamado "deleted-in azoospermia gene" ou DAZ. Estas deleções são muito pequenas para serem vistas citogeneticamente, mas observa-se nos fenotipos histológicos: ausência de células germinativas, ausência de células pós-meióticas, quantidades variadas de células germinativas em diferentes estágios incluindo espermatozóides maduros (Vogt, 1996).

Nem todos os homens com estas deleções do cromossomo Y são inférteis. Pryor et al. (1997) estudou consecutivamente 200 homens com infertilidade, dos quais 26 tinham azoospermia, 30 severa oligospermia (<5x106 espermatozóides/ml), 42 oligospermia (5 -20 x1066 espermatozóides/ml) e 102 normospermia. Em 14 destes homens (7\%), foi encontrado microdeleções do cromossomo Y, incluindo 6 com azoospermia, 3 com severa oligospermia, 4 com oligospermia e 1 com normospermia. A relação entre genótipo e fenótipo, portanto, atualmente não é nem específico, nem inteiramente claro. 0 mosaicismo das células de linhagem germinativa pode complicar ainda mais o diagnóstico, mas é provavelmente de pouca significância.

A injeção intracitoplasmática de esperma (ICSI) pode aumentar obviamente o risco da transmissão destas anormalidades para os descendentes masculinos. Kent etal. (1996), mostrou que $9 \%$ dos filhos nascidos após a ICSI, tinham deleções no cromossomo Y. Logo, os métodos diagnósticos para avaliar estas deleções no cromossomo $Y$ devem ser estabelecidos e um rastreamento de rotina deve ser realizado antes da ICSI.

Apesar do cromossomo $Y$ deter genes que são responsáveis pela organização testicular, apenas $0,5 \%$ dos homens inférteis têm alterações estruturais que são detectáveis por estudos citogenéticos (De Brackeleer et al., 1991). 


\section{FIBROSE CÍSTICA}

A fibrose cística (CF) é uma doença autossômica recessiva que afeta em torno de uma a cada 4000 crianças, na Dinamarca correspondendo a uma freqüência de portadores (heterozigotos) de 3\%. A doença é causada por mutações no gene regulador da condutância transmembrana da fibrose cística (CFTR), afetando a proteína CFTR correspondente. A fibrose cística pode ser causada por uma série de diferentes mutações, sendo a mais freqüente, a deleção de um códon na posição F 508 , o que é responsável por $90 \%$ dos casos encontrados na Dinamarca e de 70\% em outros países. (Lissens et al., 1996).

Mais de $95 \%$ dos homens com CF são também inférteis, primeiramente devido à ausência congênita bilateral dos vasos deferentes (CBAVD), que, por sua vez, contribui com $2 \%$ de toda infertilidade masculina (Lissens et al.,1996).

Nem todos os homens, entretanto, com CBAVD têm CFAFC, isso parece fazer parte de uma má formação do sistema urogenital. Estas má formações geralmente não estão associadas com fibrose cística, porém 0 risco de CBAVD nos descendentes masculinos é desconhecido. CBAVD sem mutação no gene CFTR pode ser devido a mutações em outros genes até agora não identificados (Bienvenu et al.,1997).

Geralmente, homens com CBAVD devem ser rastreados de mutações no gene CFTR, entretanto, este rastreamento é muito complexo, já que mais de 500 tipos diferentes de mutações têm sido detectadas em pacientes com CF. Analisando-se os três tipos mais freqüentes de mutações pode-se afirmar que $95 \%$ de CF será detectada. Aqueles homens, em que a única manifestação clínica é CBAVD, podem ter tipos diferentes de mutações, quando comparados com pacientes com os sintomas clássicos de CF, por isso, os protocolos para o rastreamento de homens inférteis com CBAVD podem diferir da rotina de rastreamento de pacientes com CF. Homens inférteis sem sinal de CF podem ser preferencialmente examinados por ultrassom a fim de detectar anomalias do sistema urogenital, embora o risco de doença similar nos descendentes dos homens com estas condições seja desconhecido. Outra possibilidade é restringir o rastreamento de CF para aqueles homens com ultrassonografia do sitema urogenital anormal.

Aconselhamento genético de pacientes com CF deve ser restrito a poucos centros altamente especializados e em cooperação com clínicas envolvidas com infertilidade.

\section{DIAGNÓSTICO}

Em princípio, pode haver uma ou mais razões para o rastreamento de homens inférteis com potencial para anormalidades cromossômicas:

- Alguns distúrbios genéticos com severa oligozoospermia são incompatíveis com a fertilização, mesmo usando aspiração epididimal percutânea de espermatozóides (PESA), aspiração epididimal microcirúrgica de espermatozóides (MESA), extração testicular de espermatozóides (TESE) e a injeção intracitoplasmática de espermatozóides (ICSI). Estes canais devem ser poupados de tratamentos sem esperança.

- Alguns distúrbios genéticos implicam em alto risco de passarem para a constituição genética dos descendentes masculinos, tendo como conseqüências a infertilidade masculina e anormalidades cromossômicas. Este risco deve ser avaliado antes da tentativa de fertilização ser feita, porque a fertilização com um doador de esperma pode ser uma alternativa atrativa para muitos casais ou por selecionar casais entre os quais deve ser oferecido o diagnóstico pré-implantação e pré-natal.

- Se possibilita um melhor tratamento tendo o conhecimento sobre a anormalidade específica.

E m homens com aberrações estruturais autossômicas, a taxa de sucesso da ICSI é reduzida e há um risco aumentado da perda gestacional (Assche et al.,1996). Em casos de aneuploidia de cromossomo sexual, a taxa de sucesso da ICSI é variável, mas se bem sucedida o risco de aneuploidia nos descendentes é provavelmente baixa. Sugere-se que todos os homens que queiram ter filhos e que não tenham azoospermia obstrutiva, quando encaminhados a ICSI devem ser submetidos à exame de cariótipo.

Testes diagnósticos para deleções no cromossomo $Y$ ainda não foram estabelecidos na maioria das clínicas de infertilidade. Tentativas devem ser feitas a fim de poder oferecer tal diagnóstico à todos os homens encaminhados à ICSI. A té que estas facilidades estejam disponíveis, o aconselhamento dos casais deve incluir 
informações sobre o risco de transmitir estas deleções, se presentes, para os descendentes masculinos que, nestas circunstâncias, sofrerão dos mesmos problemas como os pais inférteis. Portanto, os casais que não desejam correr este risco podem realizar fertilização através de um doador de esperma.

Várias iniciativas vêm sendo tomadas durante os últimos anos com o objetivo de assegurar qualidade no trabalho da infertilidade, incluindo o registro obrigatório de todos os ciclos de fertilização in vitro. A fim de que a sociedade continue tendo confiança na conduta do tratamento da infertilidade, em clínicas de infertilidade, tanto públicas como particulares, é necessário que elas tornem-se responsáveis em fornecer informações e aconselhamento aos casais que apresentam um risco aumentado de transmitir doenças genéticas. Sugere-se para manter a qualidade e responsabilidade:

- Um controle sistemático de qualidade dos descendentes através de novas tecnologias, incluindo testes para detectar anormalidades genéticas até então conhecidas.

- Informação adequada aos casais com potencial para transmitir doenças genéticas para seus descendentes, e as consequências destas anormalidades.

- Estabelecimento de métodos diagnósticos relevantes a fim de tornar possível selecionar aqueles casais nos quais a aplicação de novas tecnologias não parece trazer risco genético significante e, por outro lado, identificar casais nos quais este risco está aumentado, considerando-se outras alternativas.

- Estabelecimento de uma equipe de trabalho que catalise melhoramentos, assegurando qualidade ao atendimento, tanto em clínicas públicas como particulares.

- Recomendações profissionais Nórdicas padronizadas é uma opção atrativa como uma orientação para estas iniciativas.

- Realização de pesquisa.

ABSTRACT: This study are describe the diverse genetic causes of masculine infertility, the cromossomic and molecular alteration that may happen in patients with oligo or azoospermia. Its also pretends to revise the tecniques of pre-implantational diagnosis avaliable nowadays. The study is centered in genetic aspects of the masculine factor in the couples' infertility. The importance of this study is in the ethic duty of analysing case by case, when to opt for intra-citoplasmatic injection of spermatozoons (ICIS), it because a significative fraction of person with idiopatic oligo or azoospermia have genetic alterations in their spermatozoons or spermatogonias, and there is a great probability of the child to have a genetic disease. This way, the (ICIS) is not a good way to the coupler wich face this problem.

KEY WORDS: Infertility male; Genetic; Abnormalities.

RESUMEN: Describe las causas genéticas diversas de la esterilidad masculina, las alteraciones cromosómicas y moleculares que pueden pasar en pacientes con oligo o azoospermia. Además proyecta tambiém una revisión de las tecnicas de diagnóstico pre-implantacional disponible actualmente. El estudio se centra en aspectos genéticos del factor masculino en la esterilidad de las parejas. La importancia de este estudio consiste en un deber ético de analizar caso por caso, cuándo optar para la inyección del intra-citoplasmatic de espermatozoos (ICIS ), él porque una fracción significativa de individuos con oligo o azoospermia tiene alteraciones genéticas en su espermatozoos o spermatogonias y hay una gran probabilidad del niño para tener una enfermedad genética. De esta manera, el (ICIS) no es una manera buena para que las parejas enfrenten este problema.

PALABRAS CLAVE: Infertilidad masculina; Genetica; Anormalias.

\section{REFERÊNCIAS BIBLIOGRÁFICAS}

1. ANGUIANO, A et al. Congenital bilateral absence of the vas deferens: a primarily genital form of cystic fibrosis. J AMA, Chicago, v.267, p. 1794-1797, 1992.

2. ASSCHE et al. Cytogenetics so infertile men. Hum. Reprod., Oxford, v.11, supl. 4, p. 1-24, 1996.

3. AUGER, J . et al. Decline in semen quality among fertile man in Paris during the past 20 years. N. Engl. J . Med, Boston, v.332, p. 281-282, 1995. 
4. BIENVENU, T. etal. Molecular diagnosis so congenital bilateral absence os the vas deferens: analises of the CFTR gene in 64 French patients. Ann Genet, Paris, v. 40, p. 5-9, 1997.

5. CHANDLEY,A.C. The genetic basis fo male infertility Reprod Med Rev., v.4, p. 1-8, 1995.

6. JEQUIER, A.M.; HOLMES, S.C. Aetiological factors in the production of obstrutive azoospermia. Br.J . Urol., Oxford, v.56, p. 540, 1984.

7. J ONES, H.W.J r.; TONER, J .P.: The infertile couple. N. Engl.J . Med., Boston, v. 329, p. 1710, 1993.

8. KENT, F. M.G. et al. The incidence and possible relevance of Y- Linked microdeletions in babies born after intracytoplasmatic injection and their infertile fathers. Mol. Hum. Reprod., Oxford, v.2, p. 943-950, 1996.

9. KJ ESSLER, B. Karyotype meiosis and spermatogenesis in a sample of men attenting na infertily clinic. Monograph in human genetics, Basel, v.2, p. 1-74, 1996.

10. PRAUER, H.U.et al. Relevance of genetic counselling in couples prior to intracytoplasmatic sperm injection. Hum. Reprod., Oxford, v.12, p.1909-1912, 1997.

11. PRYOR, J.L. et al. Microdeletions in the Y chromossome of infertile men. N. Engl. J . Med., Boston, v. 336, p. 534-539, 1997.

12. SEIBEL, M.M. Infertility. 2.ed. New York : Appleton and Lange, 1996.

13. VOGT, P. Genetic aspects of artificial fertilization. Hum. Reprod., Oxford, v.10, suppl.1, p. 128-137, 1995.

14. VOGT, P.H. et al. Human Y chromossome azoospermia factors (AZF) mapped regions in Yq 11. Hum. Mol. Genet., Oxford, v.5, p. 933-943, 1996. 